\title{
Public health in China: An environmental and socio-economic perspective
}

\author{
Wenjing Song a, c, Yonghua Li ${ }^{\text {a, b, }{ }^{*}, \text { Zhe Hao }}{ }^{\text {a, d }}$, Hairong Li $^{\text {a, }}{ }^{* *}$, Wuyi Wang ${ }^{\text {a }}$ \\ a Key Laboratory of Land Surface Pattern and Simulation, Institute of Geographical Sciences and Natural Resources Research, Chinese Academy of Sciences, \\ Beijing 100101, China \\ ${ }^{\mathrm{b}}$ Beijing Key Laboratory of Environmental Damage Assessment and Remediation, Beijing, China \\ ${ }^{c}$ University of Chinese Academy of Sciences, Beijing 100049, China \\ d Key Laboratory of Engineering Oceanography, Second Institute of Oceanography, SOA, Hangzhou 310012, China
}

\section{H I G H L I G H T S}

- Association between health outcomes and environment and socio-economy was analysis.

- Using GWR and SR models to detect the association.

- High $\mathrm{SO}_{2}, \mathrm{PM}_{10}, \mathrm{CC} \& \mathrm{EC}$ have negative impact on public health outcomes.

- Public health outcomes show clear regional differences in China.

\section{A R T I C L E I N F O}

Article history:

Received 24 June 2015

Received in revised form

20 November 2015

Accepted 7 December 2015

Available online 18 December 2015

\section{Keywords:}

Public health

Centenarian ratio

Longevity index

Environmental and socio-economic

indicators

Stepwise regression

Geographically weighted regression

\begin{abstract}
A B S T R A C T
Despite the large literature on public health, few studies have examined the associations between public health outcomes and environmental and socio-economic factors. This study bridges this gap by demonstrating the relationships between public health and 10 selected environmental and socioeconomic factors from the spatial perspective. In particular, three public health outcomes in China are investigated, namely the number of centenarians per 100,000 people (termed the centenarian ratio), the proportion of nonagenarians of the 65 years and older population (termed the longevity index), and life expectancy at birth. We base our analysis on stepwise regression and geographically weighted regression models, with study areas of 31 provinces in China. Our results show that $\mathrm{SO}_{2}$ (sulfur dioxide) concentration decreases the centenarian ratio; $\mathrm{PM}_{10}$ (particles with diameters of $10 \mu \mathrm{m}$ or less) concentration and coal consumption (CC) per capita decrease the longevity index, and GDP (Gross Domestic Product) per capita prolongs life expectancy at birth, while energy consumption (EC) per capita decreases life expectancy at birth. Further, our findings demonstrate that public health outcomes show clear regional differences in China.
\end{abstract}

(C) 2015 Elsevier Ltd. All rights reserved.

\section{Introduction}

The proportion of long-lived individuals in a population is often used as a criterion for estimating public health (Azin et al., 2001; Huang et al., 2009), specifically the number of nonagenarians and centenarians (Franceschi and Bonafe, 2003). The elderly are much

\footnotetext{
* Corresponding author. Key Laboratory of Land Surface Pattern and Simulation, Institute of Geographic Sciences and Natural Resources Research, Chinese Academy of Sciences, Beijing 100101, China.

** Corresponding author.

E-mail addresses: yhli@igsnrr.ac.cn (Y. Li), lihr@igsnrr.ac.cn (H. Li).
}

more vulnerable and sensitive because of the existing diseases, depressed immune systems, and accumulation of toxic agents in their bodies (Balfour and Kaplan, 2002; Fischer et al., 2003). Therefore the healthy condition of centenarians can be influenced by many factors such as biological, psychosocial, environmental factors and so on (Candore et al., 2006). Studies have shown that production of centenarians appears to have an important latent effect with socioeconomic factors (Kim, 2013; Kim and Kim, 2014). IFurther the influence of air pollutants such as $\mathrm{SO}_{2}, \mathrm{PM}_{10}$, and $\mathrm{NO}_{2}$ presenting much more obvious on those aged 65 and older(Fischer et al., 2003).

Life expectancy also serves as an indicator of public health 


\author{
Abbreviations \\ CR centenarian ratio, number of centenarians per \\ 100,000 people \\ LI longevity index, the proportion of nonagenarians of \\ the 65 years and older population \\ LEB life expectancy at birth \\ $\mathrm{NO}_{2} \quad$ nitrogen dioxide \\ $\mathrm{PM}_{10} \quad$ particles with diameters of $10 \mu \mathrm{m}$ or less \\ $\mathrm{SO}_{2} \quad$ sulfur dioxide \\ NO EI nitrogen oxide emission intensity \\ $\mathrm{SO}_{2} \mathrm{EI}$ sulfur dioxide emission intensity \\ SD EI smoke and dust emission intensity \\ GDP per capita Gross Domestic Product per capita \\ $\mathrm{CV}$ per capita civilian vehicles per capita \\ EC per capita energy consumption per capita \\ CC per capita coal consumption per capita
}

because of its capacity to summarize mortality in a single measure (Auger et al., 2014).a This measure, which was proposed in the 1960s and developed in the 1970s (Manton, 1982; Sanders, 1964), can thus be used to assess morbidity in a population (Bone, 1992; Sullivan, 1971). It has been proposed that life expectancy is influenced by multiple factors, with environmental and socio-economic factors considered to be two of the most important (Christensen and Vaupel, 1996; Cournil and Kirkwood, 2001; Gonos, 2000; Hosseinpoor et al., 2012; Huang et al., 2009; Kawata, 2009; Sun et al., 2014; Wang et al., 2015b). People in more developed areas tend to have higher average life expectancy (United Nations Development Programme (Ghana), 2011) and Wang et al. (2015a) have demonstrated that life expectancy is affected by both contemporaneous and historical GDP per capita significantly. Moreover, surveys conducted in Northern China have indicated that a large increase of total suspended particulates air pollution can cause the decrease of life expectancy (Chen et al., 2013).

Since the country's economic opening up, the population's health in China has improved (Zheng et al., 2011) accompanied by significant socio-economic development and increasingly severe environmental problems. However few studies have examined the combined impact of environmental and socio-economic indicators on human public health from the spatial perspective. Therefore, investigating the spatial differences in public health associated with environmental and socio-economic factors is crucial to improving our understanding of public health.

This study estimates the association between public health outcomes and combined environmental and socio-economic indicators from the spatial perspective. We use the number of centenarians per 100,000 people (termed the centenarian ratio, or CR), the proportion of nonagenarians of the 65 years and older population (termed the longevity index, or $\mathrm{LI}$ ), and life expectancy at birth (LEB) as public health outcomes. $\mathrm{SO}_{2}$ (sulfur dioxide) emission intensity $\left(\mathrm{SO}_{2} \mathrm{EI}\right)$, nitrogen oxide emission intensity (NO EI) and smoke and dust emission intensity (SD EI) are indices measuring the air pollution from the district perspective, while $\mathrm{PM}_{10}$ (particles with diameters of $10 \mathrm{um}$ or less), $\mathrm{SO}_{2}$, and $\mathrm{NO}_{2}$ (nitrogen dioxide) are the most direct way to demonstrate the air quality. GDP (Gross Domestic Product) is used as a proxy of the socioeconomic development of a region (Lim et al., 2015). Numbers of civilian vehicles and power consumption are tremendous increase with the development of social economy and have big effect on atmospheric environment (Huang et al., 2013). So the environmental and socio- economic indicators are represented by GDP per capita, civilian vehicles per capita (CV per capita), energy consumption per capita (EC per capita), coal consumption per capita (CC per capita), $\mathrm{SO}_{2}$ emission intensity $\left(\mathrm{SO}_{2} \mathrm{EI}\right)$, nitrogen oxide emission intensity (NO $\mathrm{EI}$ ), smoke and dust emission intensity (SD EI), $\mathrm{PM}_{10}, \mathrm{SO}_{2}$, and $\mathrm{NO}_{2}$.

The major objectives of the study are to (i) demonstrate the distribution of CR, LI, and LEBat the provincial level in China from a spatial perspective; (ii) determine the most influential environmental and socio-economic indicators on CR, LI, and LEB; (iii) to analyze the spatial relationship between these environmental and socio-economic factors and public health; and (iv) compare geographically weighted regression (GWR) with stepwise regression (SR) models.

In the remainder of the paper, we first display the correlations between public health outcomes and environmental and socioeconomic indicators; then, we establish SR models in combination with GWRmodels to find the most influential indicators for public health outcomes from the spatial perspective. Next, we present the results before drawing conclusions.

\section{Materials and methods}

\subsection{Study area}

We conducted this study at the provincial level in China by taking into account the administrative divisions. Thirty-one major provinces in China were selected as the study area. The study regions are shown in Fig. 1.

\subsection{Data}

The environmental and socio-economic indicators (GDP per capita, CV per capita, EC per capita, CC per capita, $\mathrm{SO}_{2} \mathrm{EI}, \mathrm{NO} \mathrm{EI}, \mathrm{SD}$ $\mathrm{EI}, \mathrm{PM}_{10}, \mathrm{SO}_{2}$ and $\mathrm{NO}_{2}$ ) used in this study were collected from the Department of Pollution Emission Control, Ministry of Environmental Protection of the People's Republic of China (China's MEP, 2013). The data of GDP per capita, CV per capita, EC per capita, CC per capita, $\mathrm{SO}_{2} \mathrm{EI}, \mathrm{NO}$ EI and $\mathrm{SD}$ EI are all statistical data. The concentration of $\mathrm{PM}_{10}, \mathrm{SO}_{2}$ and $\mathrm{NO}_{2}$ are monitored according to the

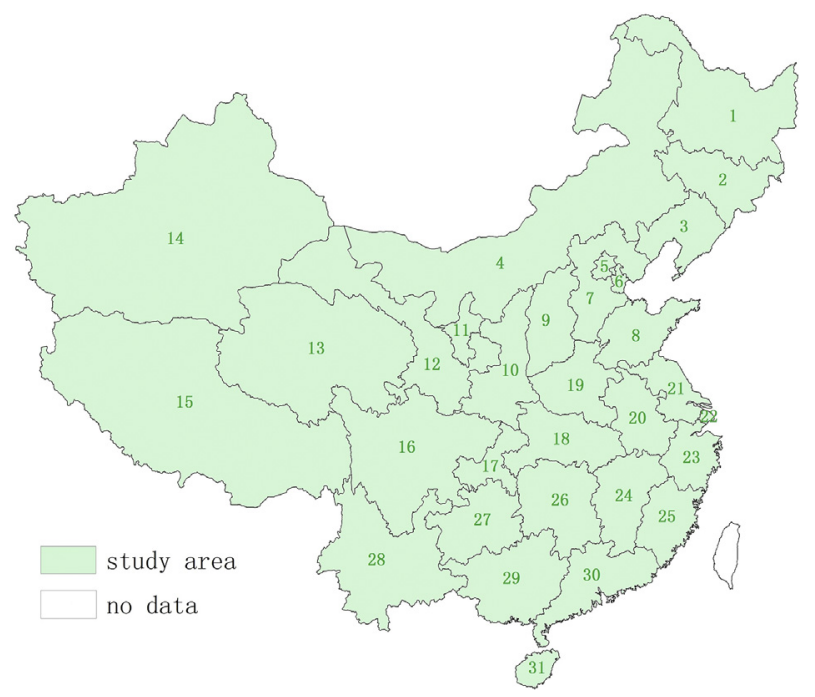

Fig. 1. Study areas: 1-Heilongjiang; 2-Jilin; 3-Liaoning; 4- Inner Mongolia; 5-Beijing; 6-Tianjin; 7-Hebei; 8-Shandong; 9-Shanxi; 10-Shanxi; 11-Ningxia; 12-Gansu; 13Qinghai; 14-Xinjiang; 15- Tibet; 16-Sichuan; 17-Chongqing; 18-Hubei; 19-Henan; 20 Anhui; 21-Jiangsu; 22-Shanghai; 23-Zhejiang; 24-Jiangxi; 25-Fujian; 26-Hunan; $27-$ Guizhou; 28-Yunnan; 29-Guangxi; 30-Guangdong; 31-Hainan. 
Gravimetric method (GB 6921-86), formaldehyde absorbingpararosaniline spectrophotometry (GB/T 15262) (or the tetrachloromercurate (TCM)-pararosaniline method (GB 8970)) and Saltzman method (GB/T 15435) respectively. LEB data were calculated from demographic data obtained from the demographic database of the sixth national population census of China (National Bureau of Statistics of China (2010)). The formula for calculating LEB was described by Wang et al. (2014a). Data on the populations of 65 years and older, nonagenarians, and centenarians were also obtained from the demographic database of the sixth national population census of China (National Bureau of Statistics of China (2010)).

\subsection{Methods}

To investigate how environmental and socio-economic factors affect public health in China, we ran two types of regression models including SR and GWR models. We began with SR models, and then ran GWR models with the included indicators from SR. And the last we compared GWR with SR models from the methodological perspective. Since the SR has been well known, in the following we only describe the theoretical background of GWR models.

SR is an automatic algorithm for selecting statistical models. When the number of potential explanatory variables is high, SR can be used to select the most influential ones as the dependent variable in linear regression models. In this study, we conduct SR models to select the best-fitted combination of environmental and socio-economic indicators for three public health outcomes.

Because SR models have fixed the relationships between the dependent and independent variables, we included the selected explanatory variables in the GWR models to address the spatial heterogeneity of the relationship between public health outcomes and the selected environmental and socio-economic indicators. GWR was first proposed by Brunsdon et al. (1996). The essence of GWR in regional analysis is that it can present spatial heterogeneity by mapping different parameters in the geographic space. In this study, GWR models were utilized to generate local regression coefficients and local $\mathrm{R}^{2}$ for each province of the study areas, which were then mapped to show the spatial variability. The GWR model can be expressed as the following function:

$y_{i}=\beta_{0}\left(u_{i}, v_{i}\right)+\sum_{k} \beta_{k}\left(u_{i}, v_{i}\right) x_{i k}+\varepsilon_{i}$

where $y_{i}$ denotes the dependent variables such as CR, LI, and LEB in this paper at location $\mathrm{i} ;\left(u_{i}, v_{i}\right)$ denotes the coordinates of the centroid at location $\mathrm{i} ; \beta_{0}\left(u_{i}, v_{i}\right)$ is the intercept for location $\mathrm{i} ; \beta_{k}\left(u_{i}, v_{i}\right)$ denotes the local parameter for independent variable $\mathrm{k}$ at location $\mathrm{i}$ (displayed as B in Table 4); $x_{i k}$ is the value of independent variable $\mathrm{k}$ at location $\mathrm{i}$; and $\varepsilon_{i}$ denotes the error term for location $\mathrm{i}$.

GWR models generate a separate regression equation for each observation in the study areas. Regression coefficients calculated by using weighted least squares can be estimated with the following weighting function (Brunsdon et al., 2002):

$\beta\left(u_{i}, v_{i}\right)=\left(\boldsymbol{X}^{T} \boldsymbol{W}\left(u_{i}, v_{i}\right) \boldsymbol{X}\right)^{-1} \boldsymbol{X}^{T} \boldsymbol{W}\left(u_{i}, v_{i}\right) \boldsymbol{Y}$

where $\beta\left(u_{i}, v_{i}\right)$ denotes the local regression coefficient at location $\mathrm{i}$; $\mathbf{X}$ is the matrix of the independent variables; $\mathbf{Y}$ is the vector of the dependent variable; and $\boldsymbol{W}\left(u_{i}, v_{i}\right)$ denotes an $\mathrm{n} \times \mathrm{n}$ matrix in which the diagonal elements are the spatial weighting of the observed samples. The spatial weighting function can be stated using the exponential distance decay form:

$$
\boldsymbol{W}\left(u_{i}, v_{i}\right)=\exp \left(\left(-d^{2}\left(u_{i}, v_{i}\right) / b^{2}\right)\right.
$$

where $\mathrm{d}\left(u_{i}, v_{i}\right)$ is the distance between location $\mathrm{i}$ and $\mathrm{j}, \mathrm{b}$ is the kernel bandwidth. Usually, the Guassian kernel is used for a better computed result. When the distance between the locations is greater than the kernel bandwidth, the weigh rapidly approaches zero.

The data in this study were analyzed by using SPSS 18.0 and ArcGIS 10.0. Correlation and SR analyses were performed using SPSS 18.0 and GWR analyses were performed using ArcGIS 10.0 using the function of "Geographically Weighted Regression" in the "Spatial Statistics Tool". Statistical significance was defined at the 5 percent level using a two-tailed test.

\section{Results and discussion}

\subsection{Correlation analysis}

We quantified Spearman's correlation coefficients (Table 1 ) to measure the correlation between CR, LI, and LEB and the environmental and socio-economic indicators.

The analysis of the Spearman correlation coefficients indicated that CR was negatively and significantly $(\mathrm{p}<0.05)$ correlated with EC per capita $(\mathrm{r}=-0.374)$, CC per capita $(\mathrm{r}=-0.572)$, and $\mathrm{SO}_{2}$ $(\mathrm{r}=-0.445)$, while LI was negatively and significantly correlated with EC per capita $(\mathrm{r}=-0.377)$, CC per capita $(\mathrm{r}=-0.588)$, and $\mathrm{SO}_{2}$ $(\mathrm{r}=-0.424)$. However, it was positively and significantly associated with NO EI $(r=0.416)$. Positive and significant correlations were also found between LEB and GDP per capita $(r=0.761)$, CV per capita $(r=0.466), \mathrm{SO}_{2}$ EI $(r=0.558)$, NO EI $(r=0.717)$, SD EI $(\mathrm{r}=0.597)$, and $\mathrm{NO}_{2}(\mathrm{r}=0.363)$.

\subsection{SR modeling}

As described in the previous section, SR modeling was performed to select the most influential explanatory variables related to public health. Table 2 shows the SR models of the three public health outcomes (CR, LI, LEB) obtained by using the 10 independent variables including GDP per capita, CV per capita, EC per capita, CC per capita, $\mathrm{SO}_{2} \mathrm{EI}, \mathrm{NO} \mathrm{EI}, \mathrm{SD}$ EI, $\mathrm{PM}_{10}, \mathrm{SO}_{2}$ and $\mathrm{NO}_{2}$. The results from the SR models show that the most influential factor(s) on CR is $\mathrm{SO}_{2}$; on $\mathrm{LI}$ are $\mathrm{PM}_{10}$ and CC per capita; and on LEB are GDP per capita and EC per capita.

For $\mathrm{CR}, \mathrm{SO}_{2}$ was the best-fitting combination of environmental and socio-economic factors. A $0.001 \mathrm{mg} / \mathrm{m}^{3}\left(1 \mu \mathrm{g} / \mathrm{m}^{3}\right)$ increase in ambient $\mathrm{SO}_{2}$ concentration resulted in a 0.0948 decrease in $\mathrm{CR}$, as explained by the SR model. The adjusted $R^{2}$ values indicated that the entire model explained 29.6 percent of the variation in $C R$.

For $\mathrm{LI}, \mathrm{PM}_{10}$ and CC per capita were the best-fitting combinations of environmental and socio-economic factors. For every $0.001 \mathrm{mg} / \mathrm{m}^{3}\left(1 \mu \mathrm{g} / \mathrm{m}^{3}\right)$ increase in ambient $\mathrm{PM}_{10}$ concentration, LI decreased by 0.0129 percent, while for every 1 ton increase in CC per capita, LI decreased by 0.078 percent, as explained by the SR model. The adjusted $R^{2}$ values indicated that the entire model explained 47.8 percent of the variation in LI.

For LEB, GDP per capita and EC per capita were the best-fitting combination of the environmental and socio-economic factors. Every 1000 RMB increase in GDP per capita could prolong LEB by $0.120 \mathrm{a}$, while every 1 ton increase in EC per capita could decrease LEB by 0.584 a, as explained by the SR model. The adjusted $R^{2}$ values indicated that the entire model explained 73 percent of the variation in LEB. The characteristics of the variables analyzed are summarized in Table 3. 
Table 1

Summary of Spearman correlations between CR, LI, and LEB and the environmental and socio-economic indicators.

\begin{tabular}{|c|c|c|c|c|c|c|c|c|c|c|}
\hline & GDP & $\mathrm{CV}$ & $\mathrm{EC}$ & $\mathrm{CC}$ & $\mathrm{SO}_{2} \mathrm{EI}$ & NO EI & SD EI & $\mathrm{PM}_{10}$ & $\mathrm{SO}_{2}$ & $\mathrm{NO}_{2}$ \\
\hline CR & 0.076 & -0.108 & $-0.374^{*}$ & $-0.572^{* *}$ & 0.091 & 0.189 & 0.004 & -0.172 & $-0.445^{*}$ & 0.136 \\
\hline LI & 0.262 & 0.002 & $-0.377^{*}$ & $-0.588^{* *}$ & 0.299 & $0.416^{*}$ & 0.220 & -0.340 & $-0.424^{*}$ & 0.178 \\
\hline LEB & $0.761^{* *}$ & $0.466^{* *}$ & 0.160 & -0.191 & $0.558^{* *}$ & $0.717^{* *}$ & $0.597^{* *}$ & -0.072 & -0.158 & $0.363^{*}$ \\
\hline GDP & 1 & $0.763^{* *}$ & $0.611^{* *}$ & $0.216^{* *}$ & $0.510^{* *}$ & $0.623^{* *}$ & $0.554^{* *}$ & 0.115 & 0.138 & $0.468^{* *}$ \\
\hline CV & & 1 & $0.749^{* *}$ & $0.434^{*}$ & $0.366^{*}$ & $0.480^{* *}$ & $0.413^{*}$ & 0.199 & 0.337 & 0.281 \\
\hline EC & & & 1 & $0.721^{* *}$ & 0.273 & 0.224 & 0.306 & 0.272 & $0.516^{* *}$ & 0.091 \\
\hline $\mathrm{CC}$ & & & & 1 & 0.220 & 0.088 & 0.244 & 0.310 & $0.695^{* *}$ & -0.019 \\
\hline $\mathrm{SO}_{2} \mathrm{EI}$ & & & & & 1 & $0.938^{* *}$ & $0.943^{* *}$ & 0.107 & 0.319 & 0.200 \\
\hline NO EI & & & & & & 1 & $0.942^{* *}$ & 0.079 & 0.172 & 0.276 \\
\hline SD EI & & & & & & & 1 & 0.128 & 0.323 & 0.181 \\
\hline $\mathrm{PM}_{10}$ & & & & & & & & 1 & $0.543^{* *}$ & $0.455^{*}$ \\
\hline $\mathrm{SO}_{2}$ & & & & & & & & & 1 & 0.152 \\
\hline $\mathrm{NO}_{2}$ & & & & & & & & & & 1 \\
\hline
\end{tabular}

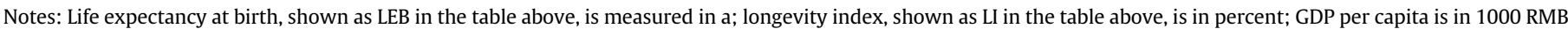

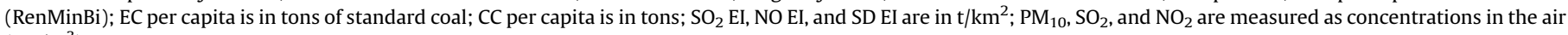
$\left(\mathrm{mg} / \mathrm{m}^{3}\right)$.

* and ${ }^{* *}$ mean that the correlation is significant at $\mathrm{p}<0.05$ and $\mathrm{p}<0.01$, respectively.

Table 2

Summary of the SR results.

\begin{tabular}{|c|c|c|c|c|c|c|c|}
\hline Dependent variable & Independent variables & B & Intercept & $\mathrm{R}^{2}$ & Adjusted $\mathrm{R}^{2}$ & SSE & Sig. \\
\hline CR & $\mathrm{SO}_{2}$ & -94.833 & 6.199 & 0.320 & 0.296 & 111.706 & 0.001 \\
\hline LI & $\mathrm{PM}_{10}, \mathrm{CC}$ & $-12.923,-0.078$ & 3.062 & 0.514 & 0.478 & 4.485 & 0.000 \\
\hline LEB & GDP, EC & $0.120,-0.584$ & 72.005 & 0.749 & 0.730 & 45.248 & 0.000 \\
\hline
\end{tabular}

Table 3

Descriptive statistics of the variables analyzed.

\begin{tabular}{lccccc}
\hline Variables & $\mathrm{N}$ & Mean & Minimum & Maximum & SD \\
\hline CR & 31 & 2.697 & 0.64 & 13.40 & 2.36 \\
LI & 31 & 1.563 & 0.70 & 2.94 & 0.56 \\
LEB & 31 & 74.916 & 68.20 & 80.30 & 2.75 \\
SO2 & 31 & 0.0355 & 0.006 & 0.058 & 0.15 \\
PM $_{10}$ & 31 & 0.0913 & 0.034 & 0.145 & 0.023 \\
GDP & 31 & 43.387 & 19.710 & 93.173 & 19.74 \\
EC & 30 & 3.702 & 1.61 & 7.96 & 1.61 \\
CC & 30 & 3.786 & 1.06 & 14.73 & 3.15 \\
\hline
\end{tabular}

southeast of the country. Hainan (13.40) had the highest CR, followed by Guangxi (6.47), Guangdong (4.12), Shanghai (4.03), and Sichuan (4.01). On the contrary, the lowest CR was in Shanxi (0.64), followed by Gansu (0.75) and Inner Mongolia (0.76).

The LI values behaved differently. Fig. 2(b) shows that the southeast coastal areas had the largest LI and that LI tended to diminish from the south to the north. They were the highest LI in Hainan (2.94 percent) Shanghai (2.71 percent), Guangdong (2.67 percent), Guangxi (2.50 percent), and Fujian (2.07 percent), as against to the lowest ones in Qinghai (0.70 percent), Gansu (0.80

Table 4

Summary of the GWR results.

\begin{tabular}{|c|c|c|c|c|c|c|c|c|}
\hline \multirow[t]{2}{*}{ Dependent variable } & \multirow[t]{2}{*}{ Independent variables } & \multicolumn{2}{|l|}{ B } & \multicolumn{2}{|c|}{ Intercept } & \multirow[t]{2}{*}{$\mathrm{R}^{2}$} & \multirow[t]{2}{*}{ Adjusted $\mathrm{R}^{2}$} & \multirow[t]{2}{*}{ SSE } \\
\hline & & Mean & Median & Mean & Median & & & \\
\hline CR & $\mathrm{SO}_{2}$ & -67.365 & -51.452 & 4.770 & 4.211 & 0.785 & 0.714 & 35.751 \\
\hline LI & $\mathrm{PM}_{10}, \mathrm{CC}$ & $-13.653,-0.0790$ & $-13.866,-0.0796$ & 3.126 & 3.148 & 0.567 & 0.505 & 4.002 \\
\hline LEB & GDP, EC & $0.115,-0.516$ & $0.106,-0.470$ & 72.178 & 72.032 & 0.862 & 0.806 & 24.873 \\
\hline
\end{tabular}

The characteristics of the variables analyzed in the SR models are summarized in Table 3, which suggests substantial variability in their values across the study area. Table 3 clearly shows that the average CR across the study areas was 2.697 . LI in the study areas ranged from 0.700 percent to 2.940 percent, with a moderate average of 1.563 percent. Mean LEB in the study areas was $74.9 \mathrm{a}$. Of the dependent variables, average $\mathrm{SO}_{2}$ and $\mathrm{PM}_{10}$ were $0.0355 \mathrm{mg} / \mathrm{m}^{3}$ and $0.09 \mathrm{mg} / \mathrm{m}^{3}$, respectively, while average GDP per capita and EC per capita were 43.387 (1000 RMB) and 3.702 tons of standard coal and average CC per capita was 3.786 tons.

Quantile maps were used to explore the spatial distribution patterns of the public health outcomes and influential socioeconomic and environmental factors (Figs. 2 and 3). Fig. 2(a) confirms that CR varied substantially across the study areas, with noticeably lower CR in northwest China and higher CR in the percent), and Inner Mongolia (0.82 percent).

Fig. 2(c) illustrates the LEB distribution across the study areas. LEB in the east of China was clearly higher than that in central regions, which was higher than that in the west. Shanghai (80.30 a) had the longest LEB, followed by Beijing (80.2 a), Tianjin (78.9 a), Zhejiang (77.7 a), and Jiangsu (76.6 a), while Tibet (68.2 a), Yunnan (69.5 a), and Qinghai (70 a) had the shortest.

Fig. 2 exhibits different distribution and variation patterns in health outcomes at the provincial level in China. It shows that, though studies have proven that China's public health has improved markedly at the national level (Zheng et al., 2011), great diversity in public health exist among different regions in China. It is interesting to note that the regions that have higher $\mathrm{CR}$, $\mathrm{LI}$ and LEB values are located in Southeast Coast of China in line with the findings of the study conducted in Italy (Magnolfi et al., 2007). That 

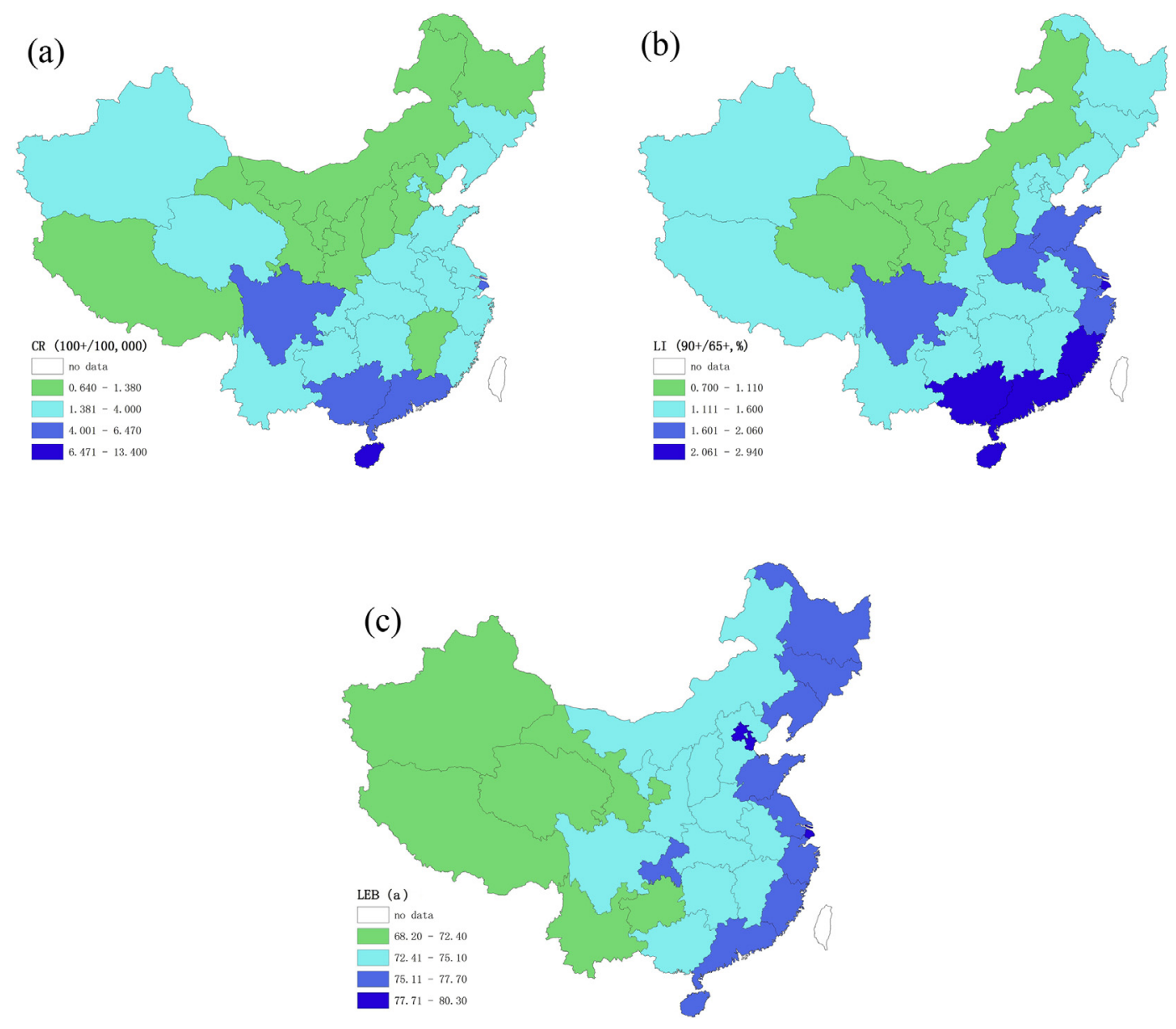

Fig. 2. The spatial distribution of public health outcomes (CR, LI, LEB) in the study areas.

is to say, the population that lives near to the sea have better health status.

Fig. 3(a) and (b) present the ambient $\mathrm{SO}_{2}$ and $\mathrm{PM}_{10}$ concentrations by study area. $\mathrm{SO}_{2}$ concentration was higher in north China Xinjiang, Liaoning, and Hebei (all $0.058 \mathrm{mg} / \mathrm{m}^{3}$ ) ranked first, followed by Shanxi $\left(0.056 \mathrm{mg} / \mathrm{m}^{3}\right)$, Shandong $\left(0.055 \mathrm{mg} / \mathrm{m}^{3}\right)$, Henan $\left(0.051 \mathrm{mg} / \mathrm{m}^{3}\right)$, and Inner Mongolia $\left(0.051 \mathrm{mg} / \mathrm{m}^{3}\right)$. The southeast regions such as Hainan $\left(0.006 \mathrm{mg} / \mathrm{m}^{3}\right)$, Fujian $\left(0.008 \mathrm{mg} / \mathrm{m}^{3}\right)$, Guangxi $\left(0.019 \mathrm{mg} / \mathrm{m}^{3}\right)$, and Guangdong $\left(0.022 \mathrm{mg} / \mathrm{m}^{3}\right)$ had lower $\mathrm{SO}_{2}$. Overall, from southwest to northeast, $\mathrm{PM}_{10}$ concentration increased first and then decreased. Xinjiang $\left(0.145 \mathrm{mg} / \mathrm{m}^{3}\right)$ had the highest $\mathrm{PM}_{10}$ concentration, followed by Gansu $\left(0.136 \mathrm{mg} / \mathrm{m}^{3}\right)$, Sichuan $\left(0.119 \mathrm{mg} / \mathrm{m}^{3}\right)$, Shanxi $\left(0.118 \mathrm{mg} / \mathrm{m}^{3}\right)$, and Beijing $\left(0.109 \mathrm{mg} / \mathrm{m}^{3}\right)$. Hainan $\left(0.034 \mathrm{mg} / \mathrm{m}^{3}\right)$, Tibet $\left(0.049 \mathrm{mg} / \mathrm{m}^{3}\right)$, and Fujian $\left(0.06 \mathrm{mg} / \mathrm{m}^{3}\right)$ had the lowest $\mathrm{PM}_{10}$ concentrations.

Fig. 3(c) and (d) illustrate the CC per capita and EC per capita distribution in the study areas. CC per capita was higher in north China, especially in Inner Mongolia (14.73 tons), Ningxia (12.52 tons), Shanxi (9.59 tons), Xinjiang (5.42 tons), and Hebei (4.32 tons). The lowest CC per capita was in Hainan (1.06 tons), followed by Beijing (1.11 tons) and Sichuan (1.47 tons). Southeast coastal areas showed higher EC per capita than interior areas and north areas were higher than south areas. The highest EC per capita was in Inner Mongolia (7.96 tons of standard coal), followed by Ningxia (7.09 tons of standard coal), Qinghai (6.18 tons of standard coal), Tianjin (5.93 tons of standard coal), and Shanxi (5.73 tons of standard coal). The lowest EC per capita was in Jiangxi (1.61 tons of standard coal), Anhui (1.90 tons of standard coal), and Hainan (1.91 tons of standard coal).

Fig. 3(e) shows the GDP per capita distribution with high values largely clustered around the southeast. Tianjin ranked first with 93,173 RMB, followed by Beijing (87,475 RMB), Shanghai $(85,373$ RMB), Jiangsu (68,347 RMB), and Inner Mongolia (63,886 RMB). Guizhou ranked last with 19,710 RMB, followed by Gansu (21,978 RMB) and Yunnan (22,195 RMB).

For $\mathrm{SO}_{2}, \mathrm{PM}_{10}$, CC per capita and EC per capita, the regional differences in China are clear (Fig. 3(a), (b), 3(c) and 3(d)), with the values in Northern China typically higher than those in Southern China. The distribution pattern of these indicators is similar to that of CR and LI. However, the variation in GDP per capita shows an increasing trend from northwest to southeast. This trend is consistent with the variation trend of LEB.

\subsection{GWR modeling}

The GWR model was used to examine the relationship between public health and the environmental and socio-economic factors in more depth. The variables included in the SR models were also used here. The mean and median values of the local regression coefficients and $R^{2}$ values included in the GWR models are summarized in Table 4 . Because of space considerations, not all the parameters estimate and local $R^{2}$ values from the GWR models can be presented here. Although the GWR regression models showed similar regression results to those of the SR models, they improved the explanatory power of the regression analysis declared by the much higher $\mathrm{R}^{2}$ values (i.e., 0.785 vs $0.296,0.567$ vs $0.514,0.862$ vs 

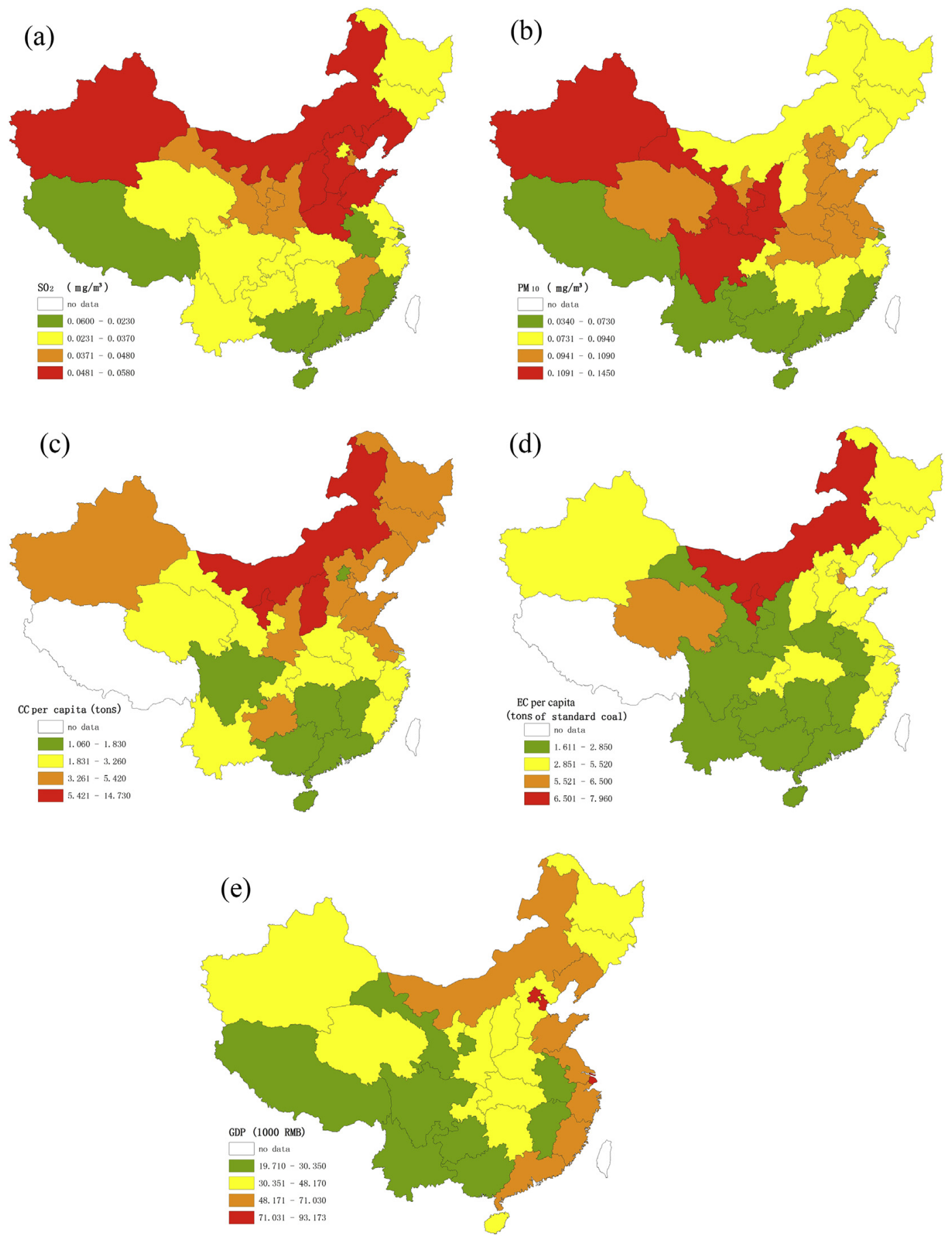

Fig. 3. The spatial distribution of the influential environmental and socio-economic factors $\left(\mathrm{SO}_{2}, \mathrm{PM}_{10}\right.$, CC per capita, EC per capita, GDP per capita) in the study areas.

0.730). This finding suggests that the GWR models outperform the SR models, implying that the spatial variation within public health should be considered.

The GWR results not only confirm the results of the SR analyses but also show significant geographic variation in the relationship between public health and the environmental and socio-economic factors. The local regression parameters of GWR models provide insights into the findings of spatial analyses. The maps of the local B coefficients and local $\mathrm{R}^{2}$ values obtained from the GWR models for CR, LI, and LEB are shown in Figs. 4-6. These maps provide a direct way to detect the spatially varying relationships between public health and the environmental and socio-economic factors.

Fig. 4(a), Fig. 5(a) and (b), Fig. 6(a), and (b) show the local B coefficients at the regression points of GWR models. The median local B coefficients can be seen to be relatively similar to those for SR. Changes in the local B coefficients for the dependent variables present clear spatial variations, implying the different degree of influence on public health outcomes. For $\mathrm{CR}$, the influence of $\mathrm{SO}_{2}$ is much higher in the southwest of China; for LI, from southeast to northwest, the influence of CC per capita and $\mathrm{PM}_{10}$ both decrease; and for LEB, the influence of EC per capita is much higher in the southwest and northeast, while that of GDP per capita is much 

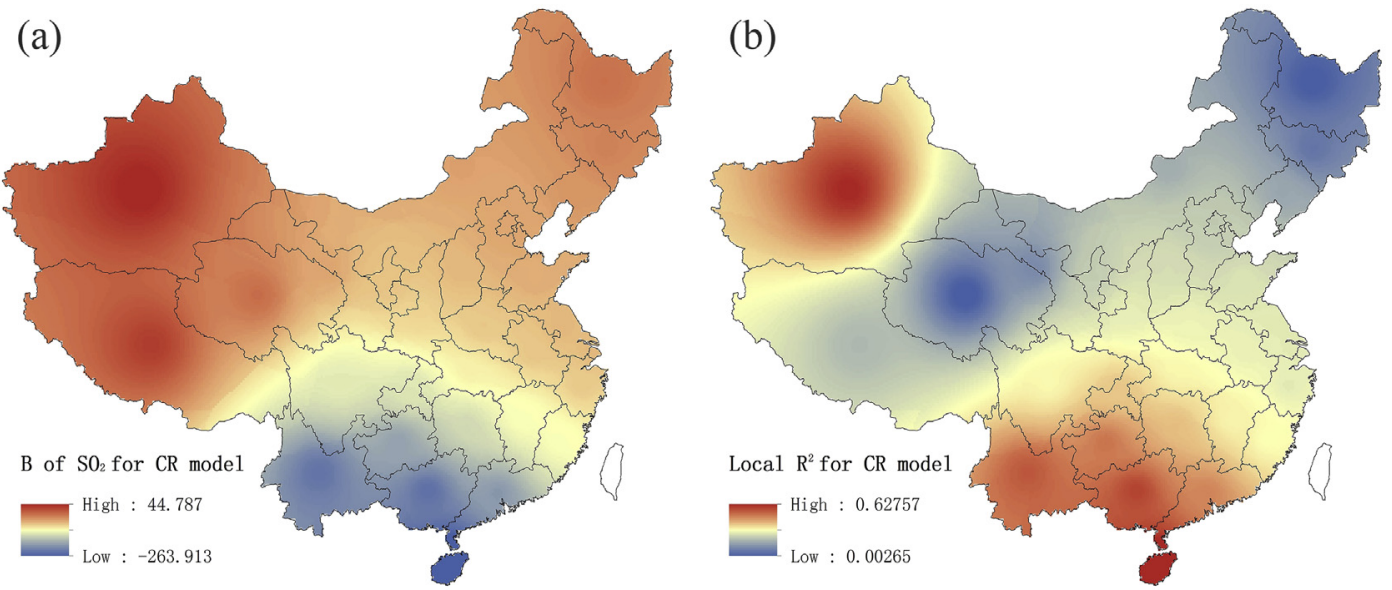

Fig. 4. Local B coefficients (a) and local R2 values (b) for CR.
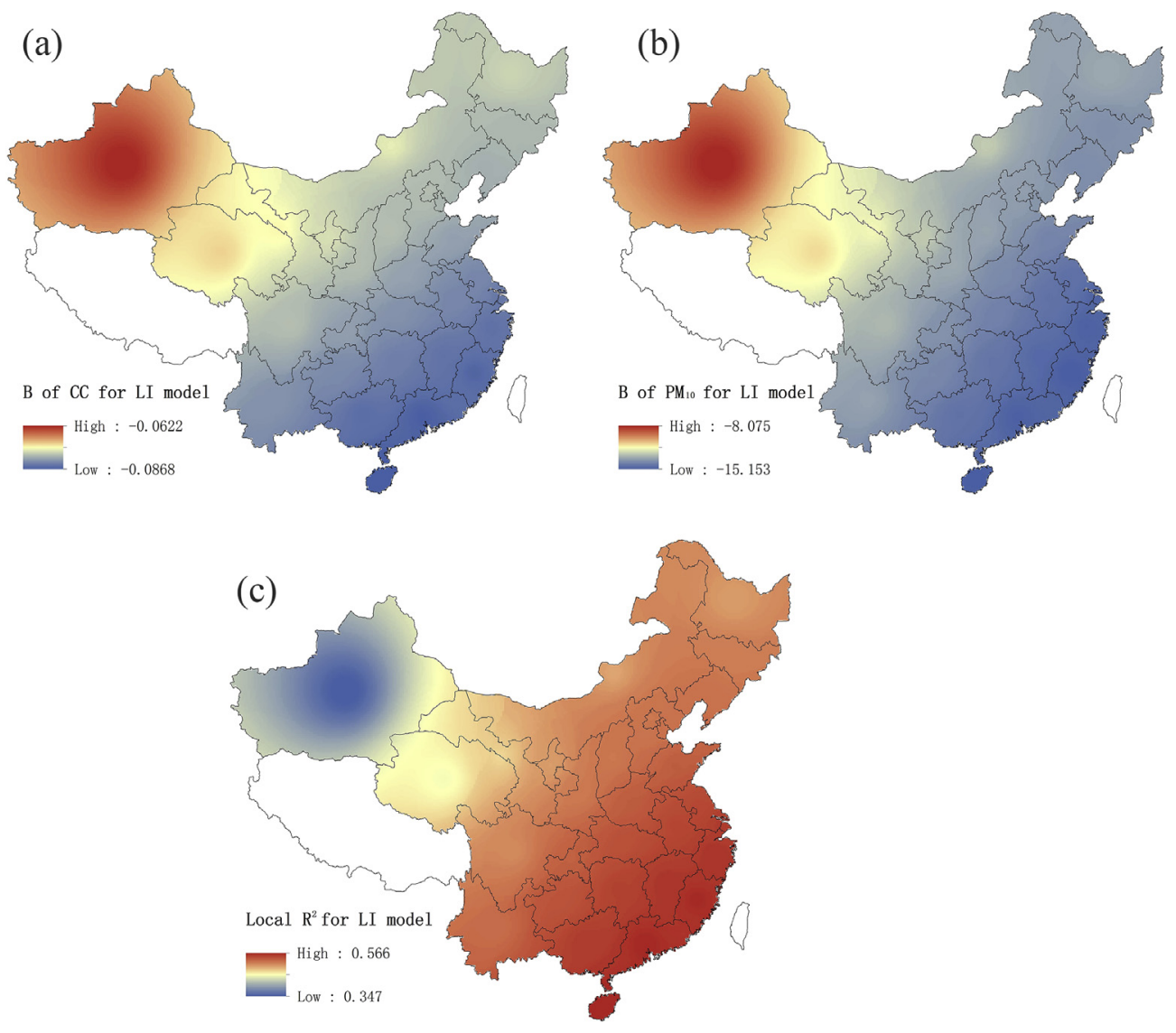

Fig. 5. Local B coefficients ((a) and (b) and local R2 values (c) for LI.

higher in the southwest.

The local $\mathrm{R}^{2}$ values generated by GWR models indicate how well the local regression model fits the observations, showing that the higher the local $\mathrm{R}^{2}$ values, the better the model performs. Fig. 4(b), Fig. 5(c) and Fig. 6(c) illustrate the local $R^{2}$ values for the GWR models. For CR, the model fit is higher in the south and northwest, while for LI, the model fit is poor in the northwest. Compared with the other study areas, the model fit is higher in the northeast for LEB.

\section{Conclusion}

To our knowledge, this is the first study to assess the relationship between environmental and socio-economic factors and public health of large scale in China. In this study, we found close associations between the examined environmental and socioeconomic factors and public health outcomes, especially CR with $\mathrm{SO}_{2}$; LI with $\mathrm{PM}_{10}$ and CC per capita; and LEB with GDP per capita and EC per capita. In addition, these connections show clear spatial characteristics according to the quantile maps and 

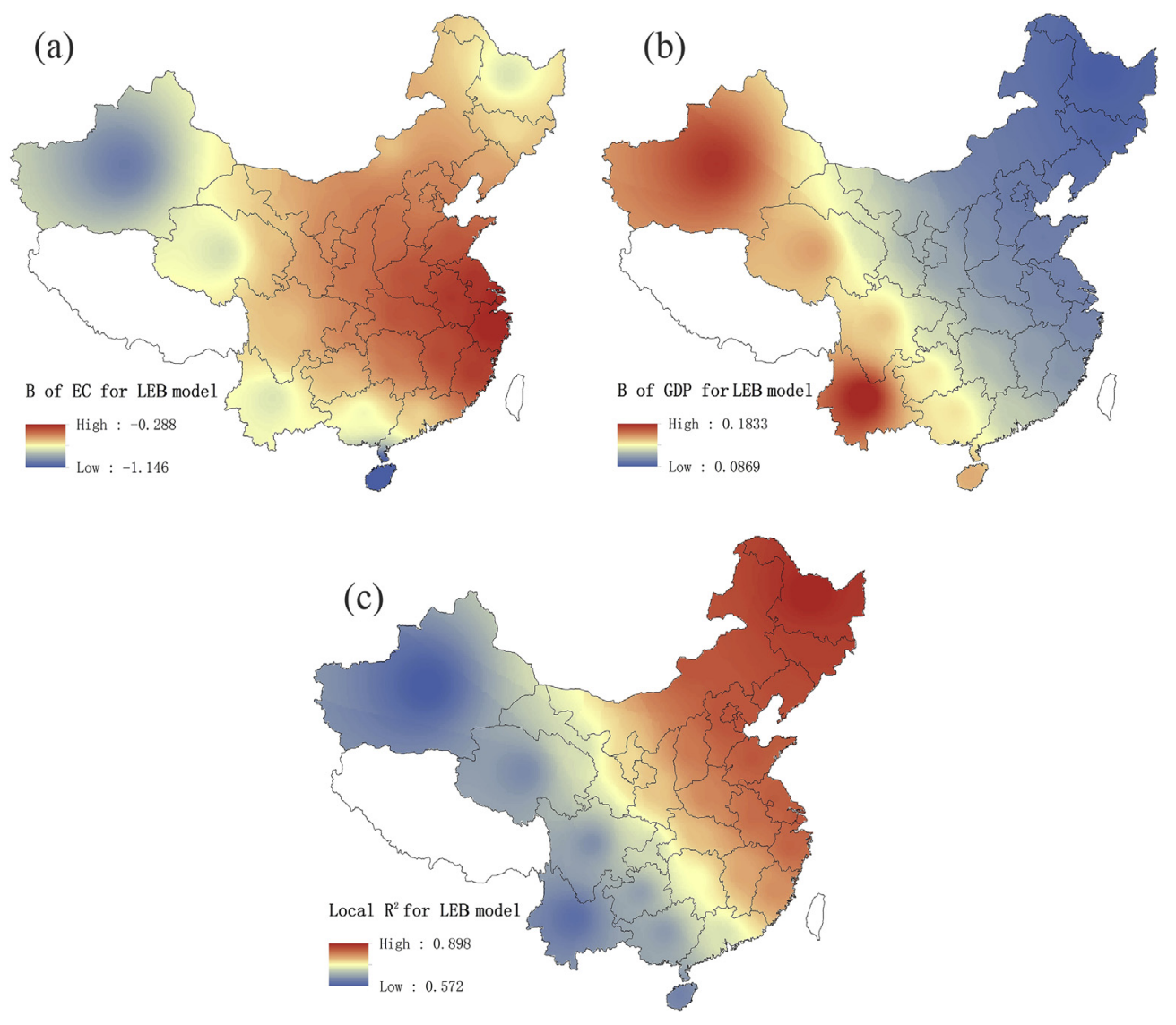

Fig. 6. Local B coefficients (a) and (b) and local R2 values (c) for LEB.

GWR results. Indeed, both the regression models used indicated that $\mathrm{SO}_{2}$ was associated with lower $\mathrm{CR}$; $\mathrm{PM}_{10}$ and $\mathrm{CC}$ per capita were associated with lower $\mathrm{LI}$; and EC per capita was associated with lower LEB, while GDP per capita was associated with higher LEB.

Previous studies have shown that $\mathrm{SO}_{2}$ and $\mathrm{PM}_{10}$ are associated with adverse health effects. An increase in $\mathrm{SO}_{2}$ concentration has been found to have a significant association with emergency room visits for cardiovascular diseases (Santos et al., 2008; Szyszkowicz, 2008). $\mathrm{PM}_{10}$ has further been proven to play an important role in cardiovascular (Pope et al., 2002) and respiratory (Hoek et al., 2012; Samet and Krewski, 2007) diseases. The findings of our study are consistent with previous studies. We found significant negative associations between $\mathrm{SO}_{2}$ and $\mathrm{PM}_{10}$ emissions and public health outcomes suggesting that $\mathrm{SO}_{2}$ and $\mathrm{PM}_{10}$ are harmful to public health. On average, every $0.001 \mathrm{mg} /$ $\mathrm{m}^{3}\left(1 \mu \mathrm{g} / \mathrm{m}^{3}\right)$ increase in ambient $\mathrm{SO}_{2}$ concentration will decrease CR by 0.0948 (SR model) and by 0.0674 (GWR model), while every $1 \mathrm{mg} / \mathrm{m}^{3}\left(1 \mu \mathrm{g} / \mathrm{m}^{3}\right)$ increase in ambient $\mathrm{PM}_{10}$ concentration will decrease LI by 0.0129 percent (SR model) and by 0.0137 percent (GWR model).

Our analysis suggests that CC per capita and EC per capita are also closely linked with public health. Studies have shown that coal consumption has significant detrimental health impact (Gohlke et al., 2011). On average, every 1 ton increase in CC per capita will decrease LI by 0.078 percent (SR model) and by 0.079 percent (GWR model), while every 1 ton increase in EC per capita will decrease LEB by $0.584 \mathrm{a}$ (SR model) and by $0.516 \mathrm{a}$ (GWR model). Coal is the most important energy resource in China, accounting for $68.4 \%$ of the total energy consumption in 2011 (Department of Energy Statistics of National Bureau of Statistics of China (2013)). The public health effect of CC per capita and EC per capita mainly result from the pollutants emitted by complete and incomplete combustion of fossil fuels. Fossil energy burning releases groups of gaseous pollutants and particulate matters contain PAHs (polycyclic aromatic hydrocarbons), $\mathrm{SO}_{2}$, heavy metals such as mercury, and other toxic components (Borm, 1997; Zhang et al., 2008; Liu et al., 2009; Li et al., 2015). These matters can pose adverse effects on human health (Li et al., 2015; Bostrom et al., 2002; Zhang et al., 2009).

In addition, a high GDP per capita benefits public health. Places with higher GDP can provide better access to health care for people. The results of our study show that, on average, every increase in 1000 RMB GDP per capita will prolong LEB by 0.120 a (SR model) and by 0.115 a (GWR model). This finding is consistent with previous studies: GDP per capita is closely connected with economic status and suggest that economic status influences life expectancy (Song et al., 2010).

Finally, from a methodological perspective, we found that the GWR models were better at illustrating the study's results according to their much higher $\mathrm{R}^{2}$ values implying spatial variation within public health in China. We showed that the GWR models explained 78.5 percent, 56.7 percent, and 86.2 percent of the variance for the three GWR models, respectively, while the SR models accounted for only 29.6, 51.4, and 73.0 percent of the variance.

Additionally, three limitations of our study should be noted. First, we excluded Tibet from LI and LEB in the GWR models because the lack of data on CC per capita and EC per capita in Tibet. 
Second, different distances among provinces might have impact on the weights of observed samples, and thus influence the local B coefficients of GWR models. Third, our study only investigated the environmental and socio-economic factors with three public health outcomes. A more comprehensive study of public health is thus needed in further research.

In conclusion, our study provided insights into the relationship between environmental and socio-economic factors and public health outcomes, showing that clear regional differences exist in China's public health. Regional health problems are a comprehensive reflection of the environment, society, economy, health, and development (Wang et al., 2014b). Strengthening the government's leadership role in health development in China is therefore of crucial importance. The results of our study can thus provide recommendations for China's public health policymakers.

\section{Acknowledgments}

Wenjing Song, Yonghua Li, Wuyi Wang designed the paper, Wenjing Song, Zhe Hao collected the data, and Hairong Li instructed the use of GWR. This paper was supported by the National Natural Science Foundation of China (No. 41171082 \& 41371118). Further support was provided by the Science and Technology Service Network Initiative Project of the Chinese Academy of Sciences (KFJ-EW-STS-015).

\section{References}

Auger, N., Feuillet, P., Martel, S., Lo, E., Barry, A.D., Harper, S., 2014. Mortality inequality in populations with equal life expectancy: Arriaga's decomposition method in SAS, stata, and excel. Ann. Epidemiol. 24, 575-580.

Azin, A.L., Zeldi, I.P., Smirnov, A.V., Shagibalov, R.Z., 2001. Aging and longevity as indicators of ecological health of the environment. Russ. J. Ecol. 32, 216-219.

Balfour, J.L., Kaplan, G.A., 2002. Neighborhood environment and loss of physical function in older adults: evidence from the Alameda county study. Am. J. Epidemiol. 155, 507-515.

Bone, M.R., 1992. International efforts to measure health expectancy. J. Epidemiol Community Health 46, 555-558.

Borm, P.J., 1997. Toxicity and occupational health hazards of coal fly ash (CFA). A review of data and comparison to coal mine dust. Annu. Occup. Hyg. 41 659-676.

Bostrom, C.E., Gerde, P., Hanberg, A., Jernstrom, B., Johansson, C., Kyrklund, T., Rannug, A., Tornqvist, M., Victorin, K., Westerholm, R., 2002. Cancer risk assessment, indicators, and guidelines for polycyclic aromatic hydrocarbons in the ambient air. Environ. Health Perspect. 110, 451-488.

Brunsdon, C., Fotheringham, A.S., Charlton, M.E., 1996. Geographically weighted regression: a method for exploring spatial nonstationarity. Geogr. Anal. 28 $281-298$.

Brunsdon, C., Fotheringham, A.S., Charlton, M.E., 2002. Geographically Weighted Regression: The Analysisi of Spatially Varying Relationships. Wiley, Chichester.

Candore, G., Balistreri, C.R., Listi, F., Grimaldi, M.P., Vasto, S., Colonna-Romano, G. Franceschi, C., Lio, D., Caselli, G., Caruso, C., 2006. Immunogenetics, gender, and longevity. Ann. N. Y. Acad. Sci. 1089, 516-537.

Chen, Y., Ebenstein, A., Greenstone, M., Li, H., 2013. Evidence on the impact of sustained exposure to air pollution on life expectancy from China's Huai river policy. Proc. Natl. Acad. Sci. U. S. A. 110, 12936-12941.

China's MEP, 2013. Environmental Data Handbook of China. Department of Pollution Emission Control. Ministry of Environmental Protection of the People's Republic of China, p. 2013.

Christensen, K., Vaupel, J.W., 1996. Determinants of longevity: Genetic, environmental and medical factors. J. Intern. Med. 240, 333-341.

Cournil, A., Kirkwood, T.B.L., 2001. If you would live long, choose your parents well. Trends Genet. 17, 233-235.

Department of Energy Statistics of National Bureau of Statistics of China, 2013. China Energy Statistical Yearbook of 2012. China Statistical Press, Beijing.

Fischer, P., Hoek, G., Brunekreef, B., Verhoeff, A., van Wijnen, J., 2003. Air pollution and mortality in The Netherlands: are the elderly more at risk? Eur. Respir. J. Suppl. 40, 34s-38s.

Franceschi, C., Bonafe, M., 2003. Centenarians as a model for healthy aging. Biochem. Soc. Trans. 31, 457-461.

Gohlke, J.M., Thomas, R., Woodward, A., Campbell-Lendrum, D., Pruss-Ustun, A. Hales, S., Portier, C.J., 2011. Estimating the global public health implications of electricity and coal consumption. Environ. Health Perspect. 119, 821-826.

Gonos, E.S., 2000. Genetics of aging: lessons from centenarians. Exp. Gerontol. 35, $15-21$.

Hoek, G., Pattenden, S., Willers, S., Antova, T., Fabianova, E., Braun-Fahrlaender, C.,
Forastiere, F., Gehring, U., Luttmann-Gibson, H., Grize, L., Heinrich, J., Houthuijs, D., Janssen, N., Katsnelson, B., Kosheleva, A., Moshammer, H., Neuberger, M., Privalova, L., Rudnai, P., Speizer, F., Slachtova, H., Tomaskova, H., Zlotkowska, R., Fletcher, T., 2012. PM10, and children's respiratory symptoms and lung function in the PATY study. Eur. Respir. J. 40, 538-547.

Hosseinpoor, A.R. Williams, J.S., Amin, A de Carvalho, I.A., Beard, J., Boerma, T. Kowal, P., Naidoo, N., Chatterji, S., 2012. Social determinants of self-reported health in women and men: understanding the role of gender in population health. PLoS One 7.

Huang, B., Zhao, Y.C., Sun, W., Yang, R., Gong, Z., Zou, Z., Ding, F., Su, J., 2009. Relationships between distributions of longevous population and trace elements in the agricultural ecosystem of Rugao county, Jiangsu, China. Environ. Geochem. Health 31, 379-390.

Huang, J.P., Zhou, C.H., Lee, X.H., Bao, Y.X., Zhao, X.Y., Fung, J., Richter, A., Liu, X., Zheng, Y.Q., 2013. The effects of rapid urbanization on the levels in tropospheric nitrogen dioxide and ozone over East China. Atmos. Environ. 77, 558-567.

Kawata, Y., 2009. Socioeconomic factors influencing longevity in Japan. Atl. Econ. J. 37 (1), 113-114.

Kim, J.I., 2013. Social factors associated with centenarian rate (CR) in 32 OECD countries. BMC Int. Health Hum. Rights 13, 16.

Kim, J.I., Kim, G., 2014. Factors affecting the survival probability of becoming a centenarian for those aged 70 , based on the human mortality database: income, health expenditure, telephone, and sanitation. BMC Geriatr. 14.

Li, J.S., Chen, G.Q., Hayat, T., Alsaedi, A., 2015. Mercury emissions by Beijing's fossil energy consumption: based on environmentally extended input-output analysis. Renew. Sustain. Energy Rev. 41, 1167-1175.

Lim, Y.H., Bell, M.L., Kan, H.D., Honda, Y., Guo, Y.L.L., Kim, H., 2015. Economic status and temperature-related mortality in Asia. Int. J. Biometeorology 59, 1405-1412.

Liu, W.X., Dou, H., Wei, Z.C., Chang, B., Oiu, W.X., Liu, Y., Tao, S., 2009. Emission characteristics of polycyclic aromatic hydrocarbons from combustion of different residential coals in North China. Sci. Total Environ. 407, 1436-1446.

Magnolfi, S.U., Petruzzi, E., Pinzani, P., Malentacchi, F., Pazzagli, M., Antonini, F.M., 2007. Longevity index (LI\%) and centenarity index (CI\%): new indicators to evaluate the characteristics of aging process in the Italian population. Archives Gerontology Geriatrics 44, 271-276.

Manton, K.G., 1982. Changing concepts of morbidity and mortality in the elderly population. Milbank Meml. Fund Q. Health Soc. 60, 183-244.

National Bureau of Statistics of China, 2010. Tabulation on the 2010 Population Census. China Statistic Press, Beijing, China.

Pope, C.A., Burnett, R.T., Thun, M.J., Calle, E.E., Krewski, D., Ito, K., Thurston, G.D., 2002. Lung cancer, cardiopulmonary mortality, and long-term exposure to fine particulate air pollution. Jama-journal Am. Med. Assoc. 287, 1132-1141.

Samet, J., Krewski, D., 2007. Health effects associated with exposure to ambient air pollution. J. Toxicol. Environ. Health-Part 70, 227-242.

Sanders, B.S., 1964. Measuring community-health levels. Am. J. Public Health Nation's Health 54, 1063-1070.

Santos, U.P., Terra-Filho, M., Lin, C.A., Pereira, L.A.A., Vieira, T.C.B., Saldiva, P.H.N., Braga, A.L.F., 2008. Cardiac arrhythmia emergency room visits and environmental air pollution in Sao Paulo. J. Epidemiol. Community Health 62, 267-272.

Song, X.M., Gong, C., Zheng, X.Y., 2010. Chinese life expectancy and policy implications. Procedia - Soc. Behav. Sci. 2, 7550-7555.

Sullivan, D.F., 1971. Single index of mortality and morbidity. Hsmha Health Rep. 86, $347-354$.

Sun, L., Lin, J., Du, H., Hu, C., Huang, Z., Lv, Z., Zheng, C., Shi, X., Zhang, Y., Yang, Z., 2014. Gender-specific DNA methylome analysis of a Han chinese longevity population. Biomed Res. Int. 2014, 1-9.

Szyszkowicz, M., 2008. Ambient air pollution and daily emergency department visits for ischemic stroke in Edmonton, Canada. Int. J. Occup. Med. Environ. Health 21, 295-300.

United Nations Development Programme (Ghana), 2011. [Name of District]: Human Development Report, 2011 : Resource Endowment, Investment Opportunities and the Attainment of MDGs. United Nations Development Programme Ghana Office, Accra.

Wang, L., Wei, B., Li, Y., Li, H., Zhang, F., Rosenberg, M., Yang, L., Huang, J., Krafft, T., Wang. W. 2014a. A study of air pollutants influencing life expectancy and longevity from spatial perspective in China. Sci. Total Environ. 487, 57-64.

Wang, W., Yang, L., LI, H., He, Z., 2014b. Integrated Analysis on Regional Development Environment and Health in China. China Environmental Press p.213.

Wang, S.B., Luo, K.L., Liu, Y.L., Zhang, S.X., Lin, X.X., Ni, R.X., Tian, X.L., Gao, X., 2015a. Economic level and human longevity: spatial and temporal variations and correlation analysis of per capita GDP and longevity indicators in China. Archives Gerontology Geriatrics 61, 93-102.

Wang, S.B., Luo, K.L., Liu, Y.L., 2015b. Spatio-temporal distribution of human lifespan in China. Sci. Rep. 5.

Zhang, Y., Schauer, J.J., Zhang, Y., Zeng, L., Wei, Y., Liu, Y., Shao, M., 2008. Characteristics of particulate carbon emissions from real-world Chinese coal combustion. Environ. Sci. Technol. 42, 5068-5073.

Zhang YX. Tao, S., Shen, H.Z, Ma, J.M. 2009. Inhalation exposure to ambient polycyclic aromatic hydrocarbons and lung cancer risk of Chinese population. Proc. Natl. Acad. Sci. 106, 21063-21067.

Zheng, X.Y., Song, X.M., Chen, G., You, Y.Z., Ren, Q., Liu, J.F., Zhang, L., Tan, L., Wei, J.H., Chen, Q.Y., 2011. Health inequalities during 20 years of rapid economic development in China (1980-2000): a mortality analysis. Biomed. Environ. Sci. 24, 329-334. 